\title{
Effect of acupuncture on post-hemorrhoidectomy pain: a randomized controlled trial
}

This article was published in the following Dove Press journal:

Journal of Pain Research

\section{Junyi $\mathrm{Wu}^{\prime}$ \\ Bei Chen² \\ Xuan Yin' \\ Ping Yin' \\ Lixing Lao ${ }^{3,4}$ \\ Shifen $X u^{\prime}$}

'The Acupuncture Department, Shanghai Municipal Hospital of Traditional Chinese Medicine, Shanghai University of Traditional Chinese Medicine, Shanghai, People's Republic of China; ${ }^{2}$ The Acupuncture Department, Tong Ren Hospital, Shanghai Jiao Tong University School of Medicine, Shanghai, People's Republic of China; ${ }^{3}$ School of Chinese Medicine, The University of Hong Kong, Hong Kong, People's Republic of China; ${ }^{4}$ University of Maryland School of Medicine, Baltimore, MD, USA
Correspondence: Shifen Xu

The Acupuncture Department, Shanghai Municipal Hospital of Traditional Chinese Medicine, No. 274 Middle Zhijiang Road, Shanghai, China, 20007I

Tel +8656639828

Email xu_teacher2006@I26.com

Lixing Lao

School of Chinese Medicine, The

University of Hong Kong, 10 Sassoon

Road, Pokfulam, Hong Kong, China

Tel +85 239176476

Email Ixlaol@hku.hk
Objectives: To observe the clinical efficacy and safety of electroacupuncture (EA) in relieving pain after hemorrhoidectomy treatment for mixed hemorrhoids.

Design: This was a randomized controlled trial.

Methods: We conducted a single-center, single-blind, and randomized controlled clinical trial. Seventy-two patients with mixed hemorrhoids who had undergone hemorrhoidectomy were randomly assigned to the following 2 groups: the EA treatment group (EA) received surround needling with EA ( $n=36)$, and the control group received sham acupuncture (SA) treatment $(n=36)$. The treatment was conducted within 15 min after the completion of the surgery and lasted for $30 \mathrm{~min}$. The pain intensity was recorded by using the visual analog scale as the primary outcome. Secondary outcomes were verbal rating scale and Wong-Baker Faces Pain Rating. These measurements were evaluated at 11 time points: once every hour in the first $8 \mathrm{~h}$ after the treatment, 24 and $48 \mathrm{~h}$ after the treatment, and at the first defecation. Besides, quality of life was measured by Symptom Checklist-90 Scale at 24 and $48 \mathrm{~h}$ follow-ups.

Results: The EA group had significantly lower visual analog scale scores at the 3 time points of $6,24 \mathrm{~h}$, and during the defecation $(p<0.05)$. Verbal rating scale showed a significantly lower score in the treatment group compared to the SA group at $4 \mathrm{~h}$ after the treatment as well as during defecation $(p<0.05)$. The Wong-Baker Faces Pain Rating scores of EA group were significantly lower at 5,7 , and $8 \mathrm{~h}$ after treatment and during defecation $(p<0.05)$ compared with those of SA group.

Conclusion: Acupuncture is effective in alleviating postoperative pain in patients who have undergone hemorrhoidectomy.

Keywords: acupuncture, hemorrhoids, hemorrhoidectomy, postoperative pain

\section{Introduction}

Hemorrhoids, which can be categorized as internal hemorrhoids (originating above the dentate line and covered by anal mucosa), external hemorrhoids (originating below the dentate line and covered by anoderm), and mixed hemorrhoids, is a disease with a high incidence and reoccurrence rate. ${ }^{1-3}$ Conventional hemorrhoidectomy is the most widely performed operation and considered the "gold standard" in preventing recurrence. ${ }^{4}$ However, postoperative pain is one of the common symptoms after hemorrhoidectomy, prolonging wound healing and impairing normal activities. ${ }^{5,6}$ Forrest et $\mathrm{al}^{7}$ reported serious pain in $87 \%$ of patients in the immediate postoperative period and in 33\% after 1 week; $6 \%$ patients still reported pain after 1 month. Conventional analgesic methods including nonsteroidal anti-inflammatory drugs, paracetamol, and opioids often have side effects, including dizziness, nausea, vomiting, constipation, and 
even tolerance, which might interfere with proper recovery and lead to a poor prognosis. ${ }^{8-10}$

Converging lines of research provide evidence that acupuncture is not only a single anesthetic technique but also a supplement to general anesthesia. A meta-analysis revealed the beneficial effects of acupuncture on anesthesia for craniotomy. ${ }^{11}$ In addition, acupuncture has proved to be an effective complementary treatment to relieve posttonsillectomy pain. ${ }^{12}$ However, the effect of acupuncture on relieving pain after hemorrhoidectomy is not well established. A previous study has reported that acupuncture is more effective than analgesic drugs for postoperative pain after hemorrhoidectomy; ${ }^{13}$ but the placebo effects of acupuncture were not accounted for due to the lack of a placebo group. In order to evaluate objectively the effects of acupuncture on pain after hemorrhoidectomy, a clinical trial with an improved design for placebo treatment should be undertaken.

In this study, we conducted a randomized controlled trial to evaluate the clinical effects and safety of electroacupuncture (EA) on postoperative pain following hemorrhoidectomy.

\section{Methods}

\section{Participants and recruitment}

The patients were enrolled in the anorectal department of the Shanghai Municipal Hospital of Traditional Chinese Medicine from July 2014 to December 2015. A total of 72 patients who were diagnosed with mixed hemorrhoids and underwent Milligan-Morgan hemorrhoidectomy and who were aged 18-50 years old were included in this study and randomly assigned to either the EA group $(n=36)$ or the sham acupuncture (SA) group $(\mathrm{n}=36)$.

The exclusion criteria were as follows: 1) patients with serious hematopoietic system, cardiovascular, liver, or kidney diseases; 2) pregnant or lactating females; 3) patients who failed to complete the questionnaires and were not able to follow medical orders; 4) patients who did not want to take the analgesic methods; and 5) patients who had undergone hemorrhoidectomy before.

The study protocol was approved by the research ethics board of the Shanghai Municipal Hospital of Traditional Chinese Medicine (2014SHL-KY-09). All patients were asked to sign informed consents forms, thereby agreeing to receive either kind of treatment. We followed the Consolidated Standards of Reporting Trials and Standards for Reporting Interventions in Clinical Trials of Acupuncture guidelines for designing and reporting controlled trials. ${ }^{14,15}$ Our team strictly defended the patients' legitimate rights and interests, and we were responsible for the therapeutic process.

\section{Sample size calculation}

According to the previous study with a $2.17 \pm 0.81$ visual ana$\log$ scale (VAS) score in the treatment group and a 3.05 \pm 0.79 VAS score in the control group, ${ }^{13}$ we determined to include 19 samples in each group, with a power of $90 \%$ and an experiment-wise $\alpha$ level of 0.05 . Assuming an estimated $20 \%$ dropout rate, 46 patients should be required in this project. Adding 26 patients for potential subject loss due to various reasons, 72 patients in total were enrolled. The sample size $\mathrm{N}$ of each group was estimated by the following formula:

$$
N=\left(Z_{\frac{\alpha}{2}}+Z_{\beta}\right)^{2} *\left(\frac{S_{1}^{2}+S_{2}^{2}}{\delta^{2}}\right)
$$

where $\delta$ represents the difference between the mean of 2 groups and $S$ represents the SD of the 2 groups.

\section{Randomization and allocation}

Patients who were interested in participating in this trial were interviewed first. After recruiting the participants, a random number table was generated on the computer using SPSS 19.0 to divide the participants into EA and SA groups in a ratio of 1:1. Randomization numbers were sealed in envelopes, and then physicians received the envelopes from another independent administrator who was in charge. According to the random digital cards in the envelopes, the researchers assigned the participants to either the treatment group or the control group. After that, the acupuncturists conducted the treatment.

\section{Blinding}

We applied a single-blind (patient-assessor-blinded) method. Participants were not aware of their group assignments in the trial. Researchers, including statisticians and outcome assessors, were all blinded to the patients' group assignments. Acupuncturists were not blinded to the group assignments, but they were not involved in the recruitment, randomization, outcome assessments, or data analysis. Each patient was separately treated in the therapeutic room in the anorectal department. The patients received acupuncture treatment in a lateral position on the bed during a treatment period within $15 \mathrm{~min}$ after surgery, so they were not able to see the procedure of the treatment. Since the local anesthesia used during the hemorrhoidectomy still worked, it was also hard for patients to distinguish whether they received the real or SA. 


\section{Intervention}

The intervention of EA and SA groups both started within 15 min after the completion of the surgery and lasted for $30 \mathrm{~min}$, which was when the needles were taken out. Treatments were performed after cleansing of the skin around the acupoint areas. The temperature of the therapeutic room was never below than $25^{\circ} \mathrm{C}$. The duration of the hemorrhoidectomy was $1 \mathrm{~h}$ on average. Lidocaine, a common local anesthetic, was used for the surgery.

\section{EA group}

In the EA group, needles were inserted into the skin at the 1 , $3,5,7,9$, and 11 o'clock positions, $4 \mathrm{~cm}$ away surrounding the anus. The acupuncturist rapidly pricked the tube -guided acupuncture needles into the skin, and then removed the tube. The needle was inserted perpendicular to the skin to a depth of about 10-25 $\mathrm{mm}$. The points 3 and 9 were connected to a G6805-2A EA device (Shanghai Huayi Medical Instrument Co., Ltd, Shanghai, People's Republic of China) at a rapid continuous output frequency $(50 \mathrm{~Hz})$, with an intensity set according to the patient's tolerance.

\section{SA group}

In the SA group, the needling tools and acupoints were the same as those used in the EA group. The acupuncturist pressed the tube on the point with one hand, while the other hand tapped the bottom of the tube. Patients felt a "needle insertion," but no needle was actually inserted into the skin. The EA device was placed to the side, turned on with the power light on; the outputs of the device were not connected to any needles.

Any patient who refused acupuncture and asked for analgesic drugs was given 2 kinds of painkillers (Compound Aminopyrine Phenacetin Tablets, which contains $150 \mathrm{mg}$ of amidopyrine, $150 \mathrm{mg}$ of paracetamol, $50 \mathrm{mg}$ of caffeine, and $15 \mathrm{mg}$ of phenobarbital) via the oral route. The pain index of these patients after taking painkillers were regarded as missing data. Intention to treat-last observation carried forward analysis was performed to evaluate these patients' pain by carrying the last observations before the medication.

\section{Quality control}

The trial was conducted under the supervision of 2 departments: Shanghai Municipal Hospital of Traditional Chinese Medicine and Shanghai Academy of Education Science. Researchers input the collected data immediately on the ResMan website. The Clinical Research Center of Drugs of
Shanghai University of TCM worked as the data monitoring team to identify problems during the trial, examine collected data, and control bias. Meanwhile, a qualified clinical trial expert was invited to monitor the study.

\section{Outcome measurements}

\section{Primary outcome}

After treatment, the pain intensity was evaluated by using the VAS to assess the quantification. ${ }^{16,17}$ The higher the score is, the higher the level is. VAS was measured at 11 different times: once every hour during the first $8 \mathrm{~h}$ after the treatment, once, respectively, at 24 and $48 \mathrm{~h}$ after the treatment, and once at the first defecation. If any patient asked for analgesic drugs, the time was recorded.

\section{Secondary outcomes}

Wong-Baker Faces Pain Rating (WB) Scale ${ }^{18}$ and verbal rating scale (VRS) were also administered at different time points to evaluate the pain levels of the patients. ${ }^{19}$

The anxiety subscale and diet and sleep subscale from the Symptom Checklist-90 Scale were assessed 24 and 48 $\mathrm{h}$ after the intervention. ${ }^{20}$ The Symptom Checklist-90 Scale contains 10 items for anxiety and 7 items for eating and sleeping respectively. All the indicators were measured through questionnaires. Higher scores indicate higher pain intensity or lower life quality.

\section{Statistical analysis}

All analysis was performed on the intention-to-treat population of participants who had at least 1 treatment. Missing data was replaced according to the principle of the last observation carried forward, and we used the Cochran-Mantel-Haenszel method and the two-sided Student's $t$-test to conduct the analysis for the ordinal categorical index (WB and VRS) and the continuous index (VAS), respectively. The $\chi^{2}$ statistics were calculated for the WB and VRS indices. Wilcox rank sum test was used to test the significance of life quality measurements. We calculated $95 \%$ CI for VAS and each measure was summarized by mean \pm SD and percentage. Analyses were performed using R software (The R Foundation, Vienna, Austria).

\section{Results}

\section{Number of participants}

From July 2014 to December 2015, we screened 85 patients in the anorectal department with mixed hemorrhoids who planned to undergo hemorrhoidectomy; among them, 6 were over 50, 3 had other serious disorders and were not suitable 
to undergo EA treatment, and 4 rejected acupuncture treatment. As a result, 73 participants were recruited and randomly assigned to the EA and SA groups (Figure 1). During the study, 3 patients asked for analgesic drug because of sharp pain after the hemorrhoidectomy. Other patients completed the study without adverse events.

\section{Baseline information}

Baseline features of the 2 groups are presented in Table 1. Hemorrhoids were further graded based on their appearance and degree of prolapsed as follows: 1) Grade I: nonprolapsing hemorrhoids; 2) Grade II: prolapsing hemorrhoids on straining but reducing spontaneously; and 3) Grade III: prolapsing hemorrhoids requiring manual reduction. ${ }^{21}$ There were no significant differences identified in demographic and clinical characteristics between the 2 groups $(p>0.5)$. No significant difference was found in the baseline pain levels before the invention between treatment group and control group.
Table I Demographic and clinical characteristics of the ITT population

\begin{tabular}{llll}
\hline Variables & EA $(\mathbf{n = 3 6})$ & SA $(\mathbf{n = 3 6})$ & $\mathbf{p}$-value \\
\hline Age, years & $40.19 \pm 6.55$ & $40.44 \pm 6.75$ & $0.873^{\mathrm{a}}$ \\
Gender, male & $15(0.42)$ & $18(0.50)$ & $0.478^{\mathrm{a}}$ \\
Hemorrhoid stage & & & $0.773^{\mathrm{a}}$ \\
$\quad$ Grade I & $8(0.22)$ & $9(0.25)$ & \\
Grade II & $10(0.28)$ & $10(0.28)$ & \\
$\quad$ Grade III & $18(0.50)$ & $17(0.47)$ & \\
Acupuncture history/years & $20(0.56)$ & $12(0.33)$ & $0.057^{\mathrm{a}}$ \\
Bleeding level & & & $0.296^{\mathrm{a}}$ \\
$\quad$ None & $22(0.61)$ & $19(0.53)$ & \\
Little & $12(0.33)$ & $13(0.36)$ & \\
Medium & $2(0.06)$ & $3(0.08)$ & \\
Heavy & $0(0)$ & $1(0.03)$ & \\
Pain before surgery & & & $0.589^{\mathrm{a}}$ \\
None & $13(0.36)$ & $10(0.28)$ & \\
Little & $16(0.44)$ & $14(0.39)$ & \\
Medium & $3(0.08)$ & $12(0.33)$ & \\
Heavy & $4(0.1 \mathrm{I})$ & $0(0)$ & \\
\hline
\end{tabular}

Note: ${ }^{\mathrm{C}} \mathrm{CMH}$ test was applied to analyze the ordinal categorical data. Abbreviations: CMH, Cochran-Mantel-Haenszel; EA, electroacupuncture; ITT, intention to treat; SA, sham acupuncture.

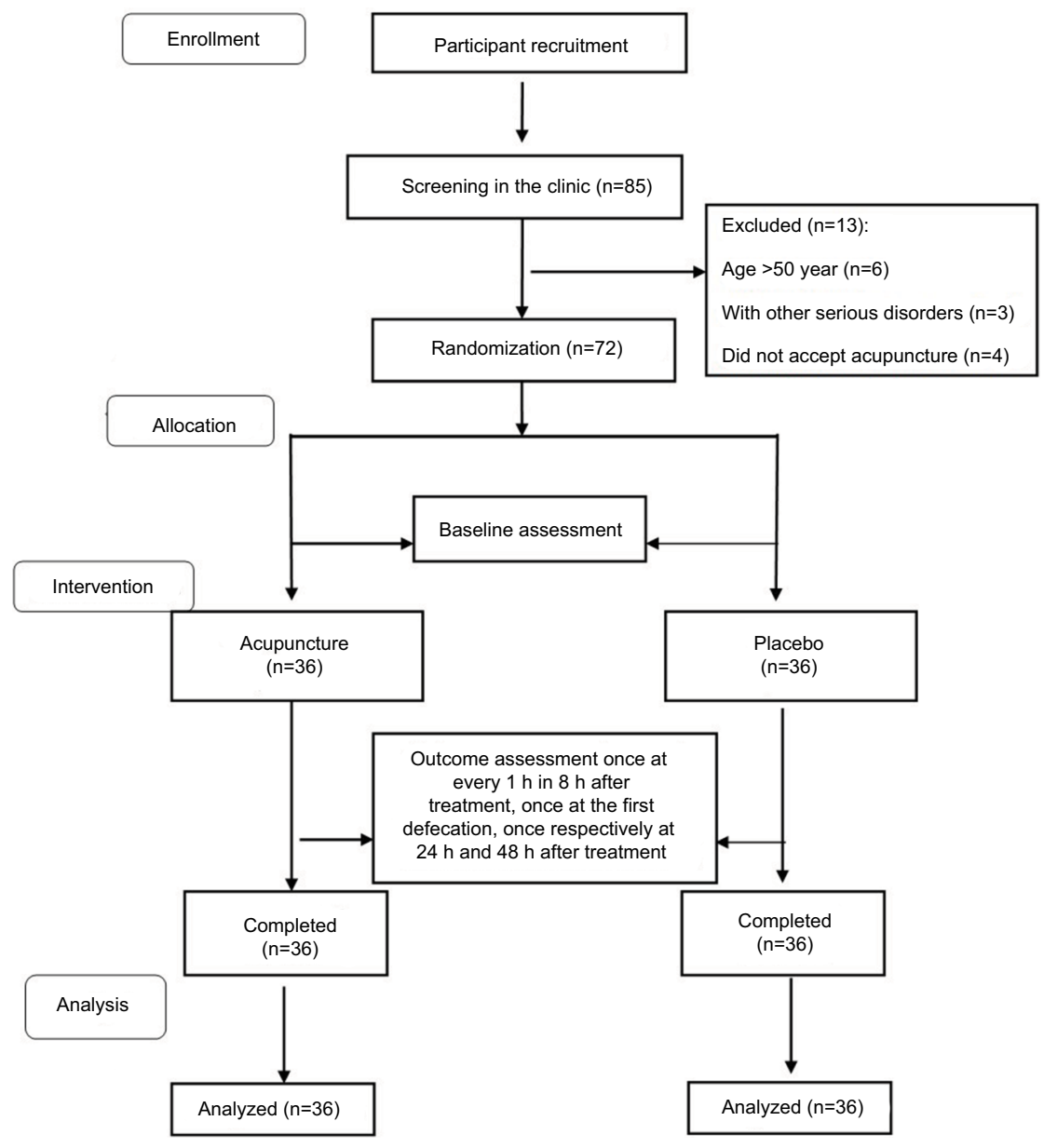

Figure I Participant selection flowchart. 


\section{Outcomes}

\section{Pain levels}

The VAS index of the EA group was significantly lower, compared to that of the SA group. Outcome analysis showed that EA group had lower VAS scores at $6 \mathrm{~h}$ after the treatment ( $p=0.033,95 \% \mathrm{CI}=-0.720,-0.031)$. The VAS scores were also lower in the EA group at $24 \mathrm{~h}$ follow-up as well as during the first defecation (Table 2, Figure 2). There were also significant differences between EA group and SA group in VRS and WB, especially during the first defecation. The VRS levels are significantly lower in the EA group than in the SA group at 4 hours after the treatment as well as during defecation $\left(\chi^{2}=4.469\right.$ and $5.997 ; p=0.035$ and 0.014 , respectively, Tables 3 and 4$)$. Similar results can also be observed in the WB index in the EA group. Compared to the SA group, the EA group has significantly lower WB levels at 5 hours posttreatment $\left(\chi^{2}=5.686, p=0.017\right)$, at 7 hours posttreatment $\left(\chi^{2}=6.441, p=0.011\right)$, at 8 hours posttreatment $\left(\chi^{2}=6.043\right.$, $p=0.014)$, and during first defecation $\left(\chi^{2}=5.164, p=0.023\right)$.

However, there were no differences between the EA group and the SA group in the first $3 \mathrm{~h}$ after treatment. The betweengroup difference of VAS, VRS, and WB were not significant

Table 2 Changes of VAS between the 2 groups with time and during the defecation time point

\begin{tabular}{|c|c|c|c|c|c|c|}
\hline \multirow[t]{2}{*}{ Variables, VAS } & \multicolumn{2}{|c|}{ EA $(n=36)$} & \multicolumn{2}{|c|}{ SA $(n=36)$} & \multirow[t]{2}{*}{$95 \% \mathrm{Cl}$} & \multirow[t]{2}{*}{$p$-value } \\
\hline & Mean & SD & Mean & SD & & \\
\hline $\mathrm{I} \mathrm{h}$ & 2.597 & 1.251 & 2.872 & 1.414 & $-0.903,0.353$ & 0.385 \\
\hline $2 \mathrm{~h}$ & 2.442 & 1.032 & 2.872 & 1.279 & $-0.977,0.116$ & 0.121 \\
\hline $3 \mathrm{~h}$ & 2.222 & 0.980 & 2.631 & 0.971 & $-0.867,0.050$ & 0.080 \\
\hline $4 \mathrm{~h}$ & 2.242 & 0.909 & 2.586 & 0.670 & $-0.720,0.032$ & 0.072 \\
\hline $5 \mathrm{~h}$ & 2.167 & 0.887 & 2.456 & 0.627 & $-0.65 \mathrm{I}, 0.073$ & 0.115 \\
\hline $6 \mathrm{~h}$ & 2.114 & 0.853 & 2.489 & 0.582 & $-0.719,-0.031$ & $0.033^{\mathrm{a}}$ \\
\hline $7 \mathrm{~h}$ & 2.225 & 0.820 & 2.622 & 0.931 & $-0.810,0.015$ & 0.059 \\
\hline $8 \mathrm{~h}$ & 2.347 & 0.925 & 2.808 & 1.056 & $-0.928,0.006$ & 0.053 \\
\hline $24 \mathrm{~h}$ & 1.075 & 0.655 & 1.513 & 0.660 & $-0.748,-0.130$ & $0.006^{\mathrm{a}}$ \\
\hline $48 \mathrm{~h}$ & 0.786 & 0.529 & 0.856 & 0.484 & $-0.308,0.169$ & 0.563 \\
\hline Defecation & 1.222 & 0.641 & 1.892 & 0.883 & $-1.036,-0.311$ & $<0.00 \mathrm{I}^{\mathrm{b}}$ \\
\hline
\end{tabular}

Notes: VAS in control group (SA) was compared to that in treatment group (EA). ${ }^{a} t$-test was used and showed a significant level of 0.05 ( $p<0.05$ ). ${ }^{b} t$-test was used and showed a significant level of $0.0 \mathrm{I}(p<0.0 \mathrm{I})$.

Abbreviations: EA, electroacupuncture; SA, sham acupuncture; VAS, visual analog scale.

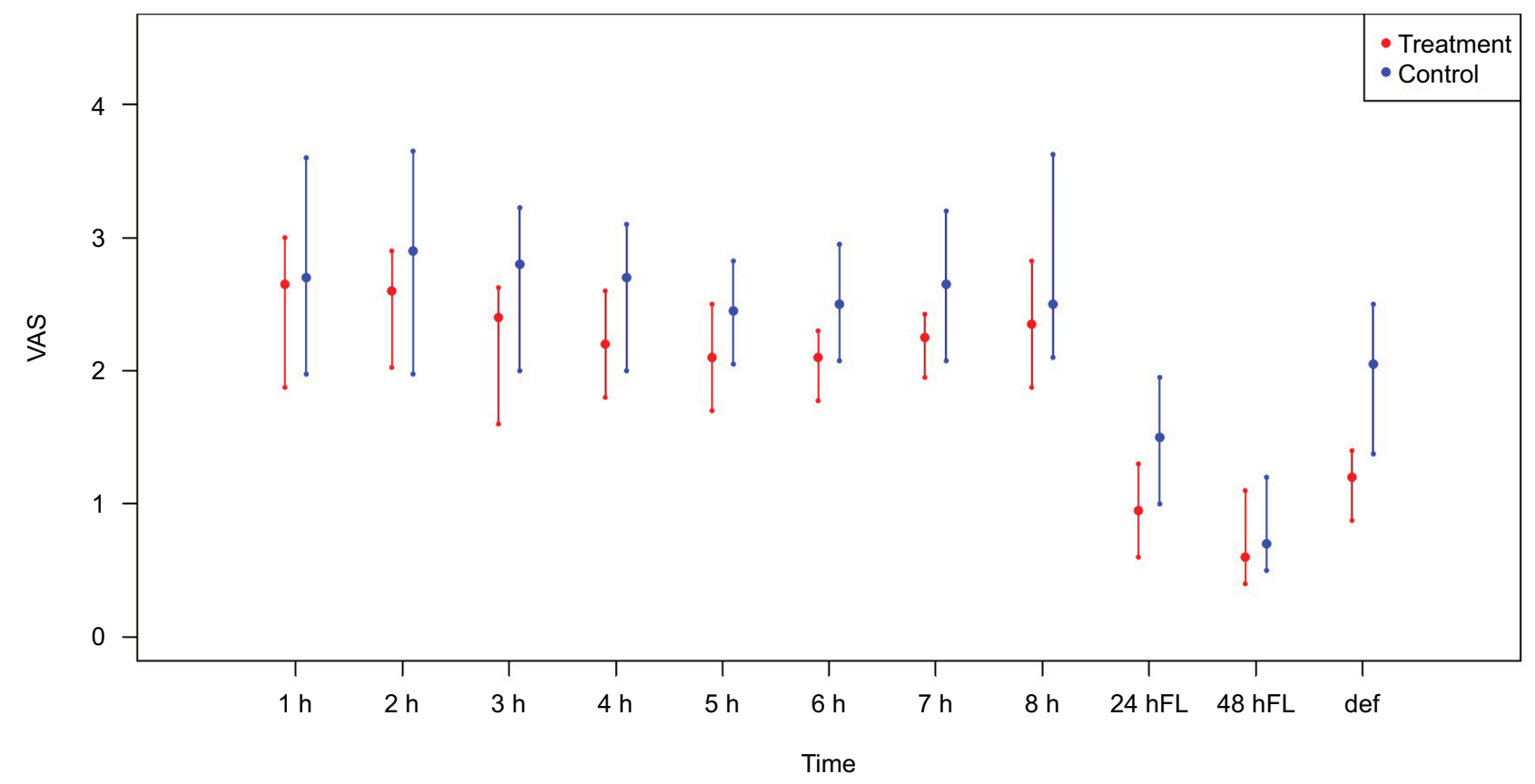

Figure 2 Mean VAS levels across the time points.

Abbreviations: VAS, visual analog scale; FL, follow-up; def, defecation. 
Table 3 Changes of VRS between 2 groups with time and during the defecation time point

\begin{tabular}{|c|c|c|c|c|c|c|c|c|}
\hline \multirow{2}{*}{$\begin{array}{l}\text { Variables, } \\
\text { VRS }\end{array}$} & \multicolumn{3}{|c|}{$\operatorname{EA}(n=36)$} & \multicolumn{3}{|c|}{ SA $(n=36)$} & \multirow[t]{2}{*}{$\chi^{2}$} & \multirow[t]{2}{*}{$p$-value } \\
\hline & 0 & I & 2 & 0 & I & 2 & & \\
\hline $\mathrm{I} \mathrm{h}$ & 4 & 28 & 4 & 3 & 27 & 6 & 0.526 & 0.468 \\
\hline $2 \mathrm{~h}$ & 4 & 29 & 3 & 3 & 27 & 6 & 0.990 & 0.320 \\
\hline $3 \mathrm{~h}$ & 4 & 31 & I & I & 31 & 4 & 3.55 & 0.060 \\
\hline $4 \mathrm{~h}$ & 3 & 32 & I & 0 & 32 & 4 & 4.469 & $0.035^{\mathrm{a}}$ \\
\hline $5 \mathrm{~h}$ & 3 & 32 & I & 0 & 36 & 0 & 1 & 0.317 \\
\hline $6 \mathrm{~h}$ & 2 & 33 & I & 1 & 35 & 0 & 0 & I \\
\hline $7 \mathrm{~h}$ & 3 & 32 & I & I & 33 & 2 & 1.270 & 0.260 \\
\hline $8 \mathrm{~h}$ & 2 & 33 & I & 0 & 34 & 2 & 1.780 & 0.182 \\
\hline $24 \mathrm{~h}$ & 10 & 26 & 0 & 5 & 31 & 0 & 2.105 & 0.147 \\
\hline $48 \mathrm{~h}$ & 24 & 12 & 0 & 21 & 15 & 0 & 0.237 & 0.626 \\
\hline Defecation & 15 & 21 & 0 & 6 & 29 & I & 5.997 & $0.014^{\mathrm{a}}$ \\
\hline
\end{tabular}

Notes: VRS in control group (SA) was compared to that in treatment group (EA). ${ }^{a} \mathrm{CMH}$ test was used and showed a significance level of 0.05 ( $p<0.05$ ).

Abbreviations: $\mathrm{CMH}$, Cochran-Mantel-Haenszel; EA, electroacupuncture; SA, sham acupuncture; VRS, verbal rating scale.

Table 4 Changes of WB between 2 groups with time and during the defecation time point

\begin{tabular}{|c|c|c|c|c|c|c|c|c|c|c|}
\hline \multirow{2}{*}{$\begin{array}{l}\text { Variables, } \\
\text { WB }\end{array}$} & \multicolumn{4}{|c|}{$\operatorname{EA}(n=36)$} & \multicolumn{4}{|c|}{ SA $(n=36)$} & \multirow[t]{2}{*}{$\chi^{2}$} & \multirow[t]{2}{*}{$p$-value } \\
\hline & 0 & 2 & 4 & 6 & 0 & 2 & 4 & 6 & & \\
\hline $\mathrm{Ih}$ & 3 & 18 & 12 & 3 & 3 & 15 & 11 & 7 & 0.967 & 0.326 \\
\hline $2 \mathrm{~h}$ & 3 & 19 & 11 & 3 & 3 & 15 & 12 & 6 & 1.007 & 0.316 \\
\hline $3 \mathrm{~h}$ & 3 & 21 & 11 & 1 & 1 & 19 & 12 & 4 & 2.262 & 0.133 \\
\hline $4 \mathrm{~h}$ & 2 & 26 & 7 & I & 0 & 21 & 13 & 2 & 3.793 & 0.051 \\
\hline $5 \mathrm{~h}$ & 2 & 30 & 3 & I & 0 & 23 & 12 & I & 5.686 & $0.017^{\mathrm{a}}$ \\
\hline $6 \mathrm{~h}$ & I & 32 & 2 & 1 & 1 & 24 & 10 & I & 3.274 & 0.070 \\
\hline $7 \mathrm{~h}$ & 2 & 32 & 2 & 0 & I & 23 & 9 & 3 & $6.44 I$ & $0.011^{a}$ \\
\hline $8 \mathrm{~h}$ & I & 32 & 2 & I & 0 & 24 & 9 & 3 & 6.041 & $0.014^{\mathrm{a}}$ \\
\hline $24 \mathrm{~h}$ & 9 & 27 & 0 & 0 & 5 & 29 & 2 & 0 & 2.536 & 0.111 \\
\hline $48 \mathrm{~h}$ & 24 & 12 & 0 & 0 & 22 & 14 & 0 & 0 & 0.806 & 0.806 \\
\hline Defecation & 10 & 25 & I & 0 & 5 & 25 & 4 & 2 & 5.163 & $0.023^{a}$ \\
\hline
\end{tabular}

Notes: WB in control group (SA) was compared to that in treatment group (EA). ${ }^{\mathrm{a}} \mathrm{CMH}$ test was used and showed a significant level of 0.05 ( $(p<0.05)$.

Abbreviations: $\mathrm{CMH}$, Cochran-Mantel-Haenszel; EA, electroacupuncture; SA, sham acupuncture; WB, Wong-Baker Faces Pain Rating.

Table 5 Life quality assessment

\begin{tabular}{llll}
\hline Variables & EA $(\mathbf{n}=36)$ & SA $(\mathbf{n}=36)$ & p-value \\
\hline Anxiety 24 h & $11.17 \pm 1.34$ & $10.61 \pm 0.93$ & 0.078 \\
Eating and sleeping 24 h & $8.67 \pm 1.10$ & $9.06 \pm 1.84$ & 0.532 \\
Anxiety 48 h & $10.94 \pm 1.22$ & $10.64 \pm 0.93$ & 0.344 \\
Eating and sleeping 48 h & $8.67 \pm 1.17$ & $8.92 \pm 1.92$ & 0.980 \\
\hline
\end{tabular}

Abbreviations: EA, electroacupuncture; SA, sham acupuncture.

$(p>0.05)$ at $1 \mathrm{~h}$ posttreatment, $2 \mathrm{~h}$ posttreatment, and $3 \mathrm{~h}$ posttreatment. There was also no between-group difference in VRS and WB at $24 \mathrm{~h}$ follow-up and at $48 \mathrm{~h}$ follow-up.

\section{Quality of life assessment}

As stated in Table 5, the anxiety levels were not significantly different between EA and SA groups both at 24 and $48 \mathrm{~h}$ after treatment $(p=0.078,0.344)$. There was no remarkable difference in the eating and sleeping conditions of patients between these 2 groups ( $p=0.532$ in $24 \mathrm{~h}$ and $p=0.979$ in $48 \mathrm{~h}$, respectively).

\section{Discussion}

In this study, we conducted a randomized clinical trial involving 72 patients who had undergone hemorrhoidectomy. We found that EA could significantly alleviate pain levels of patients after the surgery and that there was no serious adverse effect reported during the trial. Compared to the SA group, VAS, VRS, and WB scores were significantly better after EA at several measured time points. We also analyzed whether acupuncture could improve the patients' quality of life by measuring their anxiety levels as well as eating and sleeping conditions; however, it showed no remarkable improvement after EA treatment.

The scales VAS, VRS, and WB are frequently used to evaluate the pain levels before and after patients undergo different treatments. So, we used them at 11 time points after the intervention ${ }^{22}$ during this trial. Based on the results, we observed that VAS, VRS, and WB, respectively, had 3, 2, and 5 different time points reflecting the analgesic effect of 
acupuncture. We hypothesize that the analgesic effect of EA started from the time of treatment and reached its peak after $3 \mathrm{~h}$, because there was a significant difference between the 2 groups after $3 \mathrm{~h}$. These results provided strong evidence for the misunderstanding that acupuncture was a placebo therapy and had no real effect. ${ }^{23}$ We also found that although some time points after $3 \mathrm{~h}$ showed no pain difference between these 2 groups, all 3 pain measurements exhibited significant pain alleviation during first defecation. The results showed that EA was an effective treatment for relieving pain, which was quite consistent with previous findings. The Dalamagka et $\mathrm{al}^{24}$ group conducted a randomized and controlled trial to determine the effect of acupuncture treatment on 54 patients with postoperative pain after inguinal hernia repair, and they showed that there was a significant improvement in VAS after the EA treatment. In another independent randomized, placebo-controlled trial of acupuncture's effect on low back pain, VAS scores showed significant decrease after acupuncture treatment when compared with the SA treatment. ${ }^{25}$ Acupuncture has been proven to be effective in relieving pain in other diseases, but few studies focused on the analgesic effects of acupuncture on hemorrhoidectomy. Therefore, our findings, to some extent, provide complementary evidence that acupuncture has physiological mechanisms for pain relief other than the placebo effect.

It is worth mentioning that EA was used for pain relief as opposed to traditional acupuncture, and literature review supports the hypothesis that EA is superior, or at least not inferior, to manual acupuncture. ${ }^{26}$ Moreover, a number of other studies also proved that EA produced higher pain threshold elevation and better subjective evaluations of treatment effects than manual acupuncture. ${ }^{26-28}$ EA effectively alleviates both sensory and affective inflammatory pain and inhibits inflammatory and neuropathic pain.

Although our results indicated that EA treatment had an effective analgesic effect, the analgesic effects of performing acupuncture before the surgery is still unknown. We found that the onset of action of EA was $>3 \mathrm{~h}$ in this trial, but we do not know whether this was related with hemorrhoidectomy or not. To solve this puzzle, future work could assess acupuncture before the surgery and explore the complex relationships between EA, hemorrhoidectomy, and the exact onset of action of EA, which could significantly reduce pain and recovery time.

\section{Limitations}

There were some limitations in this study. First, the sample size of our trial was small, which may result in a bias of the baseline and outcome assessments. Second, the pain tolerance is different for each patient, so the measurement methods of pain levels inevitably may cause some subjective bias. The relatively short intervention and follow-up periods in this trial were also limitations. This may have also been the reason why there was no effect on the patients' quality of life. Further studies could conduct trials with larger sample sizes to reduce these limitations and achieve more significant results. Multicenter, cohort studies with more practical measurement methods can also be adopted to provide stricter clinical research designs in acupuncture clinical studies.

\section{Conclusion}

Acupuncture is an effective method to alleviate pain for hemorrhoid patients after hemorrhoidectomy.

\section{Acknowledgment}

This randomized controlled trial is funded by the Shanghai Municipal Commission of Health and Family Planning (Grant No. 2014LQ071A).

We thank Dr Andrew Zeng from the International Education College, Shanghai University of Traditional Chinese Medicine, for his editorial support.

\section{Author contributions}

Shifen $\mathrm{Xu}$ and Lixing Lao provided general support, and they were responsible for the design and implement of this trial. All authors contributed toward data analysis, drafting and critically revising the paper and agree to be accountable for all aspects of the work.

\section{Disclosure}

The authors report no conflicts of interests in this work.

\section{References}

1. Lorenzo-Rivero S. Hemorrhoids: diagnosis and current management Am Surg. 2009;75(8):635-642.

2. Schubert MC, Sridhar S, Schade RR, Wexner SD. What every gastroenterologist needs to know about common anorectal disorders. World J Gastroenterol. 2009;15(26):3201-3209.

3. Sun Z, Migaly J. Review of hemorrhoid disease: presentation and management. Clin Colon Rectal Surg. 2016;29(1):22-29.

4. Yeo D, Tan KY. Hemorrhoidectomy - making sense of the surgical options. World J Gastroenterol. 2014;20(45):16976-16983.

5. Joshi GP, Neugebauer EA; PROSPECT Collaboration. Evidence-based management of pain after haemorrhoidectomy surgery. Br J Surg 2010;97(8):1155-1168.

6. Laughlan K, Jayne DG, Jackson D, Rupprecht F, Ribaric G. Stapled haemorrhoidopexy compared to Milligan-Morgan and Ferguson haemorrhoidectomy: a systematic review. Int $J$ Colorectal Dis. 2009;24(3):335-344.

7. Forrest NP, Mullerat J, Evans C, Middleton SB. Doppler-guided haemorrhoidal artery ligation with recto anal repair: a new technique for the treatment of symptomatic haemorrhoids. Int $J$ Colorectal Dis. 2010;25(10):1251-1256. 
8. Culpepper-Morgan JA, Inturrisi CE, Portenoy RK, et al. Treatment of opioid-induced constipation with oral naloxone: a pilot study. Clin Pharmacol Ther. 1992;52(1):90-95.

9. Benyamin R, Trescot AM, Datta S, et al. Opioid complications and side effects. Pain Physician. 2008;11(Suppl 2):S105-S120.

10. Fowler PD. Aspirin, paracetamol and non-steroidal anti-inflammatory drugs. A comparative review of side effects. Med Toxicol Adverse Drug Exp. 1987;2(5):338-366.

11. Asmussen S, Maybauer DM, Chen JD, et al. Effects of acupuncture in anesthesia for craniotomy: a meta-analysis. J Neurosurg Anesthesiol. 2017;29(3):219-227.

12. Dingemann J, Plewig B, Baumann I, Plinkert PK, Sertel S. Acupuncture in posttonsillectomy pain: a prospective, double-blinded, randomized, controlled trial. HNO. 2017;65(Suppl 1):73-79.

13. Yu XH, Ma ZB. Electroacupuncture for pain after hemorhoids surgery. Shanghai J Acupuncture-Moxibustion. 2011;30(5):304-306.

14. MacPherson H, Altman DG, Hammerschlag R, et al. Revised STandards for Reporting Interventions in Clinical Trials of Acupuncture (STRICTA): extending the CONSORT statement. J Evid Based Med. 2010;3(3):140-155.

15. Schulz KF, Altman DG, Moher D. CONSORT 2010 statement: updated guidelines for reporting parallel group randomised trials. $B M J$. 2010;340:c332.

16. Carlsson AM. Assessment of chronic pain. I. Aspects of the reliability and validity of the visual analogue scale. Pain. 1983;16(1):87-101.

17. Price DD, McGrath PA, Rafii A, Buckingham B. The validation of visual analogue scales as ratio scale measures for chronic and experimental pain. Pain. 1983;17(1):45-56.

18. Shrestha M, Singh R, Moreden J, Hayes JE. Ketorolac vs chlorpromazine in the treatment of acute migraine without aura. A prospective, randomized, double-blind trial. Arch Intern Med. 1996;156(15):1725-1728.
19. Ohnhaus EE, Adler R. Methodological problems in the measurement of pain: a comparison between the verbal rating scale and the visual analogue scale. Pain. 1975;1(4):379-384.

20. Bech P, Bille J, Moller SB, Hellström LC, Østergaard SD. Psychometric validation of the Hopkins Symptom Checklist (SCL-90) subscales for depression, anxiety, and interpersonal sensitivity. J Affect Disord. 2014;160:98-103.

21. Clinical Practice Committee, American Gastroenterological Association. American Gastroenterological Association medical position statement: diagnosis and treatment of hemorrhoids. Gastroenterology. 2004;126(5):1461-1462.

22. Cleeland CS, Ryan KM. Pain assessment: global use of the Brief Pain Inventory. Ann Acad Med Singapore. 1994;23(2):129-138.

23. Zheng YC, Yuan TT, Liu T. Is acupuncture a placebo therapy? Complement Ther Med. 2014;22(4):724-730.

24. Dalamagka M, Mavrommatis C, Grosomanidis V, Karakoulas K, Vasilakos D. Postoperative analgesia after low-frequency electroacupuncture as adjunctive treatment in inguinal hernia surgery with abdominal wall mesh reconstruction. Acupunct Med. 2015;33(5):360-367.

25. Inoue $\mathrm{M}$, Kitakoji $\mathrm{H}$, Ishizaki $\mathrm{N}$, et al. Relief of low back pain immediately after acupuncture treatment - a randomised, placebo controlled trial. Acupunct Med. 2006;24(3):103-108.

26. Zhang R, Lao L, Ren K, Berman BM. Mechanisms of acupuncture-electroacupuncture on persistent pain. Anesthesiology. 2014;120(2):482-503.

27. Schliessbach J, van der Klift E, Arendt-Nielsen L, Curatolo M, Streitberger K. The effect of brief electrical and manual acupuncture stimulation on mechanical experimental pain. Pain Med. 2011;12(2):268-275.

28. Wang K, Bugge J, Bugge S. A randomised, placebo-controlled trial of manual and electrical acupuncture for the treatment of tinnitus. Complement Ther Med. 2010;18(6):249-255.
Journal of Pain Research

\section{Publish your work in this journal}

The Journal of Pain Research is an international, peer reviewed, open access, online journal that welcomes laboratory and clinical findings in the fields of pain research and the prevention and management of pain. Original research, reviews, symposium reports, hypothesis formation and commentaries are all considered for publication.

\section{Dovepress}

The manuscript management system is completely online and includes a very quick and fair peer-review system, which is all easy to use. Visit http://www.dovepress.com/testimonials.php to read real quotes from published authors. 